\title{
Local allergic rhinitis: a pediatric perspective
}

\author{
Burçin Beken $^{1 \oplus}$, Ibon Eguiluz-Gracia ${ }^{2 \oplus}$, Mehtap Yazıcıŏlu ${ }^{1 \oplus}$, Paloma Campo ${ }^{2 \odot}$ \\ ${ }^{1}$ Department of Pediatric Allergy and Immunology, Trakya University Faculty of Medicine, Edirne, Turkey; ${ }^{2}$ Allergy Unit, IBIMA- \\ Regional University Hospital of Málaga, UMA, Malaga, Spain.
}

\begin{abstract}
Local allergic rhinitis (LAR) is a differentiated rhinitis phenotype defined by perennial or seasonal rhinitis symptoms without systemic atopy. The diagnosis can be made by a positive response to the nasal allergen challenge (NAC) (the gold standard for diagnosis) in the absence of skin prick test and/or serum allergenspecific immunoglobulin E.

Clinical and epidemiological studies have demonstrated that LAR affects individuals from different countries, races, and age ranges. Several studies have shown that the onset of nasal symptoms occurs during childhood in a significant proportion of LAR individuals. Evidence of LAR has been growing, especially in pediatric and Asian populations. A review of the literature reveals that most LAR studies of pediatric populations have appeared in the last three years. The prevalence of LAR in children ranges from $3.7 \%$ to $66.6 \%$, and similar to what has been observed in adults, prevalence is higher in Western countries. Publications have shown that LAR in children can be either seasonal or perennial, and diagnosis of LAR confirmed by NAC have been reported with numerous allergens (house dust mites, pollens, molds, and dander).

These findings illustrate that LAR is an important differential diagnosis in children with presumed non-allergic rhinitis, and a through review of the very recent literature can contribute to the clinical identification and diagnosis of LAR in children with no evidence of systemic atopy, as well as update readers' knowledge of the topic.
\end{abstract}

Key words: childhood, local allergic rhinitis, nasal provocation test.

Rhinitis is an inflammation of the nasal mucosa. To manifest as chronic, two or more nasal symptoms, such as congestion, rhinorrhea, sneezing, and itching should persist for at least an hour a day for more than two weeks. ${ }^{1}$ There are mainly two subgroups of chronic rhinitis: allergic rhinitis (AR), and non-allergic rhinitis (NAR). ${ }^{2}$ Non- allergic rhinitis is a heterogenous group including occupational rhinitis, gustatory rhinitis, atrophic rhinitis, rhinitis of elderly, drug-induced rhinitis, hormonal rhinitis, coldair induced rhinitis and idiopathic rhinitis. ${ }^{2}$ Allergic rhinitis is a relatively homogeneus entity with nasal eosinophilia due to IgEmediated inflammation. ${ }^{3}$ Patients with allergic

$\triangle$ Burçin Beken

burcinbeken@gmail.com

Received 2nd August 2019, revised 19th September 2019, 24th October 2019, accepted 15th November 2019. rhinitis have positivity for at least one of markers of atopy such as skin prick test (SPT) and/or serum allergen specific $\operatorname{IgE}(\operatorname{sIgE})^{3}$, whereas NAR patients test negative for both. ${ }^{4}$ However, this classification is very simplistic, and mixed phenotypes may exist in a subgroup of patients. Some authors argue that a new classification depending on the endotypes is needed. ${ }^{5}$

Studies from 1999 to 2004 by the International Study of Asthma and Allergies in Childhood (ISAAC) revealed prevalences of rhinitis at $8.5 \%$ in children aged $6-7$ and $14.6 \%$ aged $13-$ 14. ${ }^{6}$ The 1989 Isle of Wight birth cohort of 1456 children reported prevalences of $2.8 \%$ and $11.8 \%$ in children aged 4 and 18, respectively, for rhinitis in individuals that have no allergic sensitization. The prevalences were reported as $3.4 \%$ and $27.3 \%$, respectively, for the same age groups with allergic sensitization. ${ }^{7}$ Males are more susceptible to AR, and females 
more to NAR during adolescence. Allergic rhinitis in early childhood is a risk factor for asthma development in later childhood and adulthood. ${ }^{8,9}$

Classifying chronic rhinitis simply as allergic and non-allergic had some limitations since it did not take into account the form of rhinitis that exists with local allergen-specific immunoglobulin E (sIgE) in the nasal lavage fluid/ positive nasal allergen challenge (NAC) response without apparent specific systemic sensitization, otherwise known as "entopy". ${ }^{10}$ Rondón et al. ${ }^{11}$ alternatively suggested the term "local allergic rhinitis" (LAR) for conditions with nasal Th2 inflammatory responses with the potential local production of $\operatorname{sIgE}$ and positive NAC without evidence of systemic atopy. Local allergic rhinitis shares the same clinical symptoms with AR such as sneezing, itching, obstruction, and rhinorrhea and type 2 inflamation of nasal mucosa after an allergen exposure. The patients often have ocular symptoms and high frequency of asthma. ${ }^{12,13}$

\section{Historical roots of the "local allergic rhinitis" concept}

Initial studies on LAR date back to the 1940s. In 1947, Samter et al. ${ }^{14}$ found a local reaction in non-allergic individuals after the passive transfer of nasal secretions of ragweed-allergic patients. Following the study by Tse et al. ${ }^{15}$, which showed ragweed-specific IgE in nasal secretions of ragweed-allergic patients, several studies have revealed the presence of sIgE in nasal secretions. ${ }^{6,16,17}$ Huggings and Brostoff ${ }^{16}$ was the first to show local sIgE production after a NAC in rhinitis patients with a negative SPT. In 1979, Platts-Mills ${ }^{6}$ measured the concentrations of allergen-specific immunoglobulin D ( $\operatorname{ggD})$, immunoglobulin $\mathrm{A}(\operatorname{Ig} \mathrm{A})$, and $\operatorname{IgE}$ against ryegrass pollen both in nasal secretions and serum of patients with ryegrass $A R$ and concluded that more than $90 \%$ was produced locally. In 2003, the term "entopy" was suggested by Powe et al. ${ }^{10}$ to differentiate local from systemic IgE production. Finally, in 2009, Rondón et al. ${ }^{11}$ brought the definition "local allergic rhinitis" to the literature, still used today (Fig. 1).

\section{Local Allergy: Pathophysiology}

\section{Local production of specific IgE and inflammatory mediators}

Numerous studies have shown the local production of sIgE in the nasal mucosa of AR patients. ${ }^{6,10,16,17}$ The expression of $\varepsilon$ germline gene transcriptions and messenger RNA (mRNA) for the $\varepsilon$ heavy chain in nasal B cells was shown by Durham et al. ${ }^{18}$, and the classswitch recombination to IgE in the nasal mucosa of AR patients was also demonstrated. ${ }^{19}$

Rondón et al. ${ }^{12,13}$ showed sIgE against perennial and seasonal allergens in the nasal secretions of LAR patients with a prevalence of $22 \%$ and $35 \%$, respectively.

\begin{tabular}{|c|c|c|c|c|c|c|c|}
\hline $\begin{array}{l}\text { PASSIVE TRANSFER } \\
\text { OF AR }\end{array}$ & & $\begin{array}{l}\text { NASAL SPECIFIC } \\
\text { IGE IN } \\
\text { NON_ATOPIC } \\
\text { INDIVIDUALS }\end{array}$ & & ENTOPY & $\begin{array}{l}\text { LOCAL } \\
\text { ALLERGIC } \\
\text { RHINITIS }\end{array}$ & $\begin{array}{l}\text { FIRST PEDIATRIC } \\
\text { STUDY }\end{array}$ & $\begin{array}{l}\text { FIRST } \\
\text { IMMUNOTHERAPY }\end{array}$ \\
\hline 1947 & 1970 & 1975 & 1979 & 2003 & 2009 & 2012 & 2016 \\
\hline $\begin{array}{l}\text { Samter et al. showed a } \\
\text { local reaction in } \\
\text { previously nonallergic } \\
\text { individuals after } \\
\text { transfer of ragweed AR } \\
\text { patients' nasal } \\
\text { secretions. }\end{array}$ & $\begin{array}{l}\text { Samter et al. } \\
\text { detected } \\
\text { ragweed slgE } \\
\text { in the nasal } \\
\text { secretions of } \\
\text { ragweed AR } \\
\text { patients. }\end{array}$ & $\begin{array}{l}\text { Huggins et al. } \\
\text { reported local } \\
\text { production of slgE } \\
\text { antibodies in } \\
\text { chronic rhinitis } \\
\text { patients with } \\
\text { negative skin tests. }\end{array}$ & $\begin{array}{l}\text { Platts-Mills } \\
\text { demonstrated that } \\
\text { more than } 90 \% \text { of } \\
\text { rye grass pollen } \\
\text { specific IgG, IgA and } \\
\text { lgE was produced } \\
\text { locally. }\end{array}$ & $\begin{array}{l}\text { Powe et al. } \\
\text { proposed the } \\
\text { term "entopy" } \\
\text { to differantiate } \\
\text { local from } \\
\text { systemic IgE } \\
\text { production. }\end{array}$ & $\begin{array}{l}\text { Rondon et al. } \\
\text { brought the } \\
\text { definition of } \\
\text { "Local Allergic } \\
\text { Rhinitis». }\end{array}$ & $\begin{array}{l}\text { Fuiano et al. } \\
\text { performed NAPT } \\
\text { with Alternaria to } \\
36 \text { NAR children } \\
\text { and showed nasal } \\
\text { slgE in } 24(64 \%) \text { of } \\
\text { them. }\end{array}$ & $\begin{array}{l}\text { Rondon et al. showed } \\
\text { the effectiveness of } \\
D . p t e r o n y s s i n u s \text { SCIT } \\
\text { with a RDBPC study of } \\
56 \text { patients. }\end{array}$ \\
\hline
\end{tabular}

Fig. 1. Historical roots of local allergic rhinitis. 


\section{Th2 nasal inflammatory pattern}

Non-allergic rhinitis is a heterogeneous group; several pathophysiological mechanisms for NAR have been proposed, including inflammatory and neurogenic mechanisms and also mucosal permeability changes..$^{20-24}$ Among non-atopic patients with rhinitis there are two types of rhinitis with Th2 type inflammation: LAR and non-allergic rhinitis with eosinophilia syndrome (NARES). LAR was previously mistakenly included in the NAR group. Recently, Th2-mediated inflammatory response was demonstrated in patients with LAR. ${ }^{12,13}$ Flow-cytometric studies with nasal lavage fluids have demonstrated a similar leukocytelymphocyte phenotype with increased levels of eosinophils, basophils mast cells and CD4+ $\mathrm{T}$ cells, both in AR and LAR patients during natural aeroallergen exposure. ${ }^{12,13}$

\section{Positive NAC responses}

Previous studies have shown positive NAC results based on symptom scores plus objective parameters (acoustic rhinomanometry and anterior rhinomanometry) and sIgE/ inflammatory mediators in nasal secretions up to $66 \%$ of patients previously described as NAR. ${ }^{12,13,25,26}$ An adult study from Turkey found a relatively small percentage such as $12.3 \%$ but they perfomed NAC only with $D$ pteronyssinus in 65 patients with negative allergen skin prick tests, intradermal tests and serum sIgE. ${ }^{25}$

The activation of mast cells and eosinophils and an increase in nasal sIgE after aeroallergen stimulation have been shown by kinetic studies. Patients have immediate or dual responses to NAC in terms of tryptase, eosinophilic cationic protein (ECP), and sIgE release. Tryptase levels increase 15 minutes to 1 hour after allergen exposure in immediate responders and 15 minutes to 6 hours in dual responders, and a progressive increase in nasal sIgE from 1 to 24 hours has also been found in these studies. ${ }^{11,27}$

\section{LAR evolution}

It has been a point of interest as to whether LAR evolves towards AR or if it is a distinct entity. Although, there are no controlled prospective studies in the pediatric population, there is solid evidence in adults. ${ }^{28,29}$ Rondon et al. ${ }^{29}$ conducted a 10 year follow-up study including 197 LAR patients and 130 controls. Their 5 year and 10 year follow-ups showed similar systemic sensitizations in patient and control groups (6.8 vs 4.5 in 5 year follow-up and $9.7 \%$ vs $7.8 \%$ in 10 year follow-up). ${ }^{28,29}$ After 10 years a significant proportion of LAR patiens (42\%) self reported worsening of their symptoms and their quality of life. ${ }^{29}$ A significant increase in rhinitis severity from 19 to $42 \%$ and $12 \%$ of new onset asthma as well as doubling asthma attacks were reported..$^{29}$ They also found a tendency towards polysensitization over time. The percentage of LAR patients with polysensitization was significantly higher in the 10 year follow-up compared with the baseline $(52.8 \%$ vs $36.4 \%$, respectively) The results confirm LAR as a respiratory disease with chronic course along with worsening of symptoms, development of new nasal sensitizations and new-onset asthma, deterioration of asthma control and decrease in quality of life..$^{28}$

In pediatric patients, three progression types were hypothesized by Arasi et al ${ }^{30}$ :

Progression type 1: The nasal sIgE response and mild nasal symptoms start at preschool ages (LAR), then followed by systemic IgE production at school ages (AR).

Progression type 2: Children have nasal sensitization without any symptoms at preschool age but nasal symptoms start at school ages without any systemic sensitization (LAR).

Progression type 3: Local \& systemic IgE sensitization start together without a prior 'LAR' stage. 
Regarding the type 1 progression hypothesis, there is a pediatric study reporting patients with seasonal rhinitis symptoms without serum sIgE positivity but developing systemic sensitization to grass pollen during the following second or third pollen season. ${ }^{31}$ There is not an existing study supporting the hypothesis on other progression types. With the current level of evidence we cannot go further in regards to the natural evolution of LAR in children.

\section{Comorbidities}

\section{LAR and asthma}

Current published studies suggest that asthma symptoms are reported by $20-47 \%$ of LAR patients ${ }^{12,13}$ In a recent study asthma was confirmed by methacholine test in 50\% of LAR patients. ${ }^{32}$ This proportion was found to increase to $83.3 \%$ and $57.9 \%$ in AR and NAR individuals, respectively. On the other hand, $28.8 \%$ and $83.3 \%$ of LAR and AR patients, respectively experienced a positive response in the bronchial allergen challenge (BAC), and none of the NAR or healthy control subjects did. ${ }^{32}$ Investigators also found a significant increase in airway hyperreactivity measured by metacholine test after allergen exposure. Moreover, allergen administration induced a significant increase in sputum eosinophils, monocytes and ECP in
$\mathrm{BAC}+$ patients regardless of their atopic status, with no changes in BAC-individuals. ${ }^{32}$

\section{LAR and conjunctivitis}

Patients with LAR occasionally suffer from ocular symptoms such as itching, reddness, burning and tearing during both natural exposure and NAC. ${ }^{29}$ Pollen reactive patients are more prone to experience ocular symptoms compared to dust mite reactives. ${ }^{33}$ A recent Japanese study suggests the existence of an ocular counterpart of LAR in non-atopic patients with conjunctivitis and detectable total IgE in tears. ${ }^{34}$ Unfortunately, the specificity of IgE in tears was not defined, since conjunctival allergen challenge was not performed. There is still a lack of knowledge on the nature of ocular symptoms as to whether there is a real sensitization in conjunctiva or whether the symptoms occur as a result of nasal-ocular reflexes due to allergen exposure.

\section{Evidence of LAR in children}

There are a limited number of studies investigating LAR in the pediatric population (Table I). ${ }^{35-43}$ The first pediatric study assessing nasal reactivity to allergens and nasal-specific $\mathrm{IgE}$ in non-atopic individuals was carried out by Fuiano et $a l .{ }^{35}$ in 2010 . Two years later, the same study group found that $64 \%$ of children

Table I. Studies investigating LAR in children.

\begin{tabular}{|c|c|c|c|c|c|c|}
\hline Author & Year & Country & Study group & Age (yrs) & Allergen & $\begin{array}{c}\text { Positive response } \\
\text { NAPT }(n, \%)\end{array}$ \\
\hline Fuiano et al $^{29}$ & 2012 & Italy & 36 NAR (perennial) & $4-18$ & Alternaria & $23 / 36(64 \%)$ \\
\hline $\begin{array}{l}\text { Buntarickporpan } \\
\text { et } \mathrm{al}^{30}\end{array}$ & 2015 & Thailand & 25 NAR (perennial) & $8-18$ & $\mathrm{DP}$ & $2 / 54(3.7 \%)$ \\
\hline Duman et $\mathrm{al}^{31}$ & 2016 & Turkey & $\begin{array}{c}28 \mathrm{NAR} \\
\text { (seasonal/perennial) }\end{array}$ & $5-16$ & $\mathrm{DP}, \mathrm{DF}$, grass mix & $7 / 28(25 \%)$ \\
\hline Zicari et al $^{32}$ & 2016 & Italy & 18 NAR (perennial) & $6-12$ & DP,DF, lolium & $12 / 18(66.7 \%)$ \\
\hline $\begin{array}{l}\text { Krajewska-Wojtys } \\
\text { et } \mathrm{al}^{33}\end{array}$ & 2016 & Poland & 121 NAR(seasonal) & $12-18$ & $\begin{array}{l}\text { Phleum, } \\
\text { artemisia,birch }\end{array}$ & $73 / 12(52.5 \%)$ \\
\hline Blanca-López et al ${ }^{34}$ & 2016 & Spain & 9 NAR (seasonal) & $7-18$ & Phleum & $4 / 9(44.4 \%)$ \\
\hline Ha EK et al ${ }^{35}$ & 2017 & Korea & 64 NAR (perennial) & $1-18$ & $\mathrm{DP}$ & $5 / 64(7.8 \%)$ \\
\hline Tsilochristou et al $^{36}$ & 2019 & Greece & $\begin{array}{c}24 \mathrm{NAR} \\
\text { (seasonal/perennial) }\end{array}$ & $6-18$ & $\begin{array}{l}\text { Phleum, olea, } \\
\text { alternaria, DP }\end{array}$ & $7 / 24(29 \%)$ \\
\hline
\end{tabular}


suffering from chronic rhinitis had negative SPTs but positive nasal-specific IgE against Alternaria alternata. ${ }^{36}$ The prevalence of LAR in children ranges between $3.7 \%$ and $66.7 \%$, with a lower prevalence in Asian countries (3.7$25 \%)^{37,38,42}$ compared with European countries (44.4-66.7\%)..$^{39-41}$ The allergens involved in LAR are the house dust mite (Dermatophagoides pteronyssinus), mold (Alternaria alternate), grass, birch, and dog/cat epithelia. House dust mite is the most common allergen in all LAR children worldwide. Ha et al. ${ }^{42}$ performed NAC with Dermatophagoides pteronyssinus on 145 children and diagnosed 5 of them as LAR. In a study from Turkey, Duman et al. ${ }^{38}$ performed NAC with grass mix, animal dander, molds, and cockroaches and found positive responses in 7 out of $28(25 \%)$ of patients based on a $40 \%$ decrease in nasal flow measured by anterior rhinomanometry or a $20 \%$ decrease in nasal flow with a total symptom score greater than two after allergen provocation. The largest study investigating LAR in children was performed by Krajewska-Wojtys et al. ${ }^{40}$ in which NAC with Phleum pratense, Artemisia vulgaris, and birch pollens were performed on 121 patients, aged between 12 and 18 years with confirmed NAR but having typical seasonal nasal symptoms. LAR was confirmed in $73(52.5 \%)$ patients against Phleum pratense, Artemisia vulgaris, and birch pollens in 17 (16.6\%), 6 (5.9\%), and $9(8.9 \%)$ of patients, respectively. Zicari et al. ${ }^{39}$ also found a high percentage $(66.7 \%)$ of positivity on NAC with Dermatophagoides spp. and grass pollen. They stated that nasal sIgE levels for Dermatophagoides pteronyssinus, Dermatophagoides farinae, Lolium perenne and also nasal IL-5 levels significantly increased after a positive NAC in 12 of 18 patients. The small percentage of LAR in Asian studies might be due to performing NAC with house dust mite only and differences in the objective evaluation of nasal obstruction in response to allergens.

\section{Diagnostic approach for LAR}

Since treatment varies, distinguishing between AR and NAR is important. Nasal allergological evaluation should be performed on patients with AR-like symptoms but a lack of SPT and/ or serum sIgE positivity with aeroallergens (Fig. 2).

A positive NAC in the absence of systemic atopy is the basis for diagnosing LAR. Nasal allergen challenge, a highly sensitive diagnostic method, can be used on children. There are several standardized allergen solutions produced by different companies; some of them are readyto-use solutions and some of them are sold as a

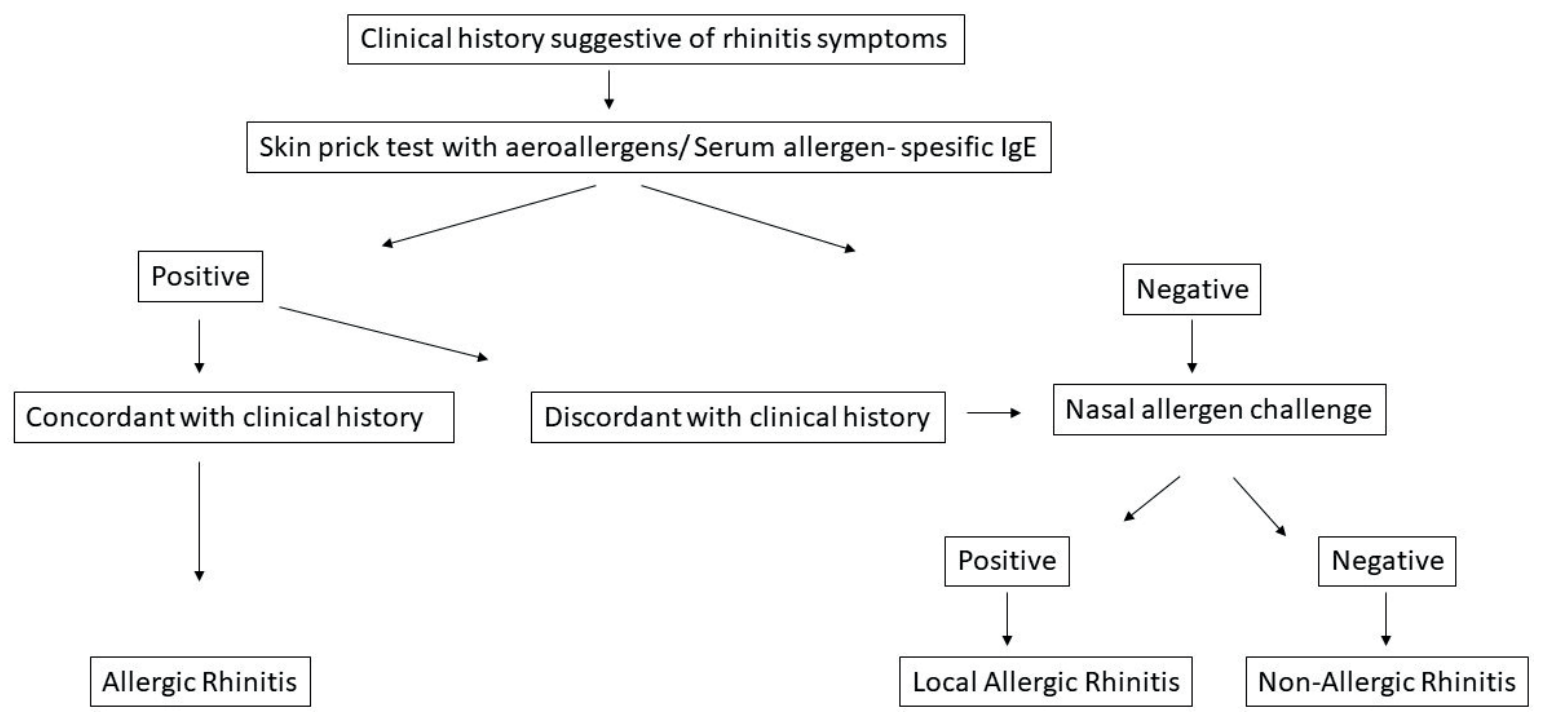

Fig. 2. Diagnostic approach for local allergic rhinitis. 
freeze-dried lyophilizate. ${ }^{44}$ Allergens should be chosen considering the clinical history such as sypmtomathic periods (perennial or seasonal) or having pets at home. Dermatophagoides pteronyssinus, Alternaria alternata, Olea europaea, Phleum pratense, cat/dog epithelia are some of the allergens that have been used for NAC in different studies. ${ }^{26,38,41,45,46}$ Several methods have been used for applying allergens. Pump-aerosol spray has been suggested as the simplest and most reliable device. ${ }^{47}$ It is adviced to apply 2 puffs $(100 \mu \mathrm{l})$ of allergen per nostril and evaluate the NAC response with symptom scores and objective assessment of nasal patency which can be measured via peak nasal inspiratory flow (PNIF), acoustic rhiometer, anterior rhinomanometry or 4-phaserhinomanometry. ${ }^{48}$ Nasal allergen challenge results should be accepted as positive in case of a strong increase of objective measurement or strong increase of symptoms or moderate increase of combined objective and symptom measurements. ${ }^{48}$ Nasal allergen challenge is a time-consuming diagnostic prosedure that needs well trained staff. To facilitate the implementation of NAC in clinical practice, Rondon et al..$^{45}$ suggested a new sensitive and reproducible NAC protocol with a sequential application of multiple aeroallergens in one session (NAC-M). This protocol is suggested as $100 \%$ concordant with the NAC performed with single allergens (NAC-S) and helpful in reducing hospital admissions required to reach the diagnosis of NAR and LAR, respectively by $75 \%$ and $55 \%$ without inducing false positive results or irritant effects. Both NAC-S and NAC-M protocols have proven to be safe. ${ }^{49}$

Determining $\operatorname{sIgE}$ in nasal secretions is a noninvasive method and is highly specific; however, it has been found to have low sensitivity in most studies (22-40\% of responses), a fact that can be attributed to the dilution effect, or other factors. ${ }^{12,13}$ A recent study performed by Meng et al..$^{50}$ found a quite high diagnostic accuracy for nasal sIgE in LAR diagnosis. They evaluated 212 children with chronic rhinitis, 14 of them had nasal sIgE $>0.35 \mathrm{kU} / \mathrm{L}$. Twelve of these patients had significantly higher nasal sIgE levels compared to controls, and also positive response to NAC, so they were defined as LAR. The sensitivity, specificity, positive predictive value, negative predictive value and diagnostic accuracy for local sIgE as a diagnostic tool for LAR was calculated as $91.7 \%, 95.1 \%, 78.6 \%$, $98.3 \%$, and $94.5 \%$, respectively.

Several samples have been used to measure nasal sIgE (secretions, scraping, brushing, tissue homogenates, etc. $)^{51}$, none of them are validated for diagnosis of LAR. Recently a Spanish research group has described a minimally invasive and simple method using the solid phase of immunoCAP for Dermatophagoides pteronyssinus, which showed a sensitivity of 44 $\%$ for LAR diagnosis. ${ }^{52}$

The basophil activation test (BAT) has also been shown to be helpful in diagnosing LAR, with $50 \%$ sensitivity and specificity greater than $90 \%$ for D. Pteronyssinus ${ }^{53}$; it is also sensitive at $66 \%$ and specific greater than $90 \%$ for O. Europea ${ }^{46}$, which means that, as an additional test, it is useful in LAR diagnosis.

The biomarkers such as eosinophilic cationic protein and tryptase have been studied in nasal secretions by several studies and found to increase approximately $50 \%$ after NAC, but have also not been validated. ${ }^{11,27}$

Therefore, both nasal sIgE, BAT and the other biomarkers should be regarded mostly as research tools which cannot be recommended for routine LAR diagnosis..$^{54,55}$

\section{Clinical relevance to differentiate LAR from AR and NAR}

Although both subgroups of chronic rhinitis have the same clinical findings such as sneezing, rhinorrhea, nasal itching and nasal obstruction, each of them have some unique features to be differentiated. Comorbidities such as rhinosinusitis, sleep disturbances, learning impairment, otitis media with effusion and reduction in quality of life may occur due to 
all chronic rhinitis subtypes. ${ }^{56}$ However, allergic comorbidities such as asthma and conjunctivitis are commonly associated with AR and LAR. In a European survey, a strong association was found between asthma development and the presence of $\mathrm{AR}$ and chronic rhinosinusitis. ${ }^{57}$ It is also known that presence of childhood AR is associated with an increased likelihood of childhood asthma. ${ }^{58}$ Current published studies have reported an increase in bronchial symptoms and lower airway symptoms after 10 years of evolution of the disease in patients with LAR. ${ }^{29}$ In addition to the aforementioned comorbidities some diagnostic methods can lead the physicians to correct diagnosis. Allergic rhinitis can easily be ruled out by SPT an/or sIgE. A further evaluation of the non-sensitized patients with NAC, nasal sIgE, and/or BAT is helpful to reveal patients with LAR. ${ }^{59}$ (Table II).

\section{Therapeutic options}

Similar to AR patients, adults and adolescents suffering from LAR respond well to topical nasal corticosteroids and oral antihistamines. ${ }^{12,13}$ Rondón et al. ${ }^{60}$ demonstrated that a sixmonth pre-seasonal subcutaneous allergen immunotherapy (AIT) with grass pollen reduced both nasal and ocular symptoms, as well as rescue medication requirement. Additionally, the number of symptom-free days were increased. The clinical and immunologic effects of AIT in LAR were shown by a randomized double-blind placebo-controlled clinical trial with $D$. pteronyssinus subcutaneous immunotherapy (SCIT). ${ }^{61}$ Randomized doubleblind placebo-controlled studies have also been conducted with Phleum Pratense ${ }^{62}$ and Betula verrucosa $a^{63}$ SCIT, revealing a statistically significant improvement in rhinoconjunctivitisaffected quality of life with both allergens and a significant clinically important improvement with Phleum pratense SCIT alone. Allergen immunotherapy also increased the allergen dose tolerated in NAC. ${ }^{62}$ Pediatric studies investigating treatment strategies, including AIT which is the sole disease-modifying treatment for IgE-mediated allergic diseases, are needed.

Local allergic rhinitis has gained more attention in pediatric circles in recent years with the introduction of diagnostic methods that can be easily applied to children, like the nasal sIgE and the BAT. Nasal allergen challenge is still the gold standard diagnostic method and performing NAC with multiple aeroallergens is both time-saving and safe. Longitudinal, prospective studies are needed to investigate the pathophysiology and evolution of LAR in terms of implementing intervention strategies from childhood.

\section{REFERENCES}

1. Roberts G, Xatzipsalti M, Borrego LM, et al. Paediatric rhinitis: position paper of the European Academy of Allergy and Clinical Immunology. Allergy 2013; 68: 1102-1116.

2. Togias A. Non allergic rhinitis. In: Akdis CA, Hellings PW, Agache I (eds). Spain: Global atlas of Allergic Rhinitis and Chronic Rhinosinusitis, 2015: 234-236.

3. Greiner AN, Hellings PW, Rotiroti G, Scadding GK. Allergic rhinitis. Lancet 2011; 378: 2112-2122.

Table II. Symptoms and in vivo/in vitro markers for rhinitis phenotypes.

\begin{tabular}{|c|c|c|c|c|c|c|}
\hline \multirow{2}{*}{ Rhinitis phenotype } & \multirow{2}{*}{ Symptoms } & \multicolumn{5}{|c|}{ In vivo/ In vitro markers } \\
\hline & & SPT & Serum sIgE & Nasal sIgE & BAT & NAC \\
\hline Allergic rhinitis & Rhinorrhea & + & $+/-$ & $+/-$ & + & + \\
\hline Local allergic rhinitis & $\begin{array}{c}\text { Sneezing } \\
\text { Nasal itching }\end{array}$ & - & - & $+/-$ & $+/-$ & + \\
\hline Non-allergic rhinitis & Nasal obstruction & - & - & - & - & - \\
\hline
\end{tabular}

BAT: basophil activation test, NAC: nasal allergen challenge, sIgE: allergen-specific IgE, SPT: skin prick test. 
4. Hellings PW, Klimek L, Cingi C, et al. Non-allergic rhinitis: position paper of the European Academy of Allergy and Clinical Immunology. Allergy 2017; 72: 1657-1665.

5. Papadopoulos NG, Guibas GV. Rhinitis subtypes, endotypes, and definitions. Immunol Allergy Clin North Am 2016; 36: 215-233.

6. Platts-Mills TA. Local production of IgG, IgA and IgE antibodies in grass pollen hay fever. J Immunol 1979; 122: 2218-2225.

7. Ait Khaled N, Pearce N, Anderson HR, Ellwood P, Montefort S, Shah J; ISAAC Phase Three Study Group. Global map of the prevalence of symptoms of rhinoconjunctivitis in children: The International Study of Asthma and Allergies in Childhood (ISAAC) Phase Three. Allergy 2009; 64: 123-148.

8. Kurukulaaratchy RJ, Karmaus W, Raza A, Matthews S, Roberts G, Arshad SH. The influence of gender and atopy on the natural history of rhinitis in the first 18 years of life. Clin Exp Allergy 2011; 41: 851859.

9. Rochat MK, Illi S, Ege MJ, et al; Multicentre Allergy Study (MAS) Group. Allergic rhinitis as a predictor for wheezing onset in school-aged children. J Allergy Clin Immunol 2010; 126: 1170-1175. e2.

10. Powe DG, Jagger C, Kleinjan A, Carney AS, Jenkins D, Jones NS. 'Entopy': localized mucosal allergic disease in the absence of systemic responses for atopy. Clin Exp Allergy 2003; 33: 1374-1379.

11. Rondón C, Fernández J, López S, et al. Nasal inflammatory mediators and specific IgE production after nasal challenge with grass pollen in local allergic rhinitis. J Allergy Clin Immunol 2009; 124: 1005-1011.e1.

12. Rondón C, Doña I, López $S$, et al. Seasonal idiopathic rhinitis with local inflammatory response and specific IgE in absence of systemic response. Allergy 2008; 63: 1352-1358.

13. Rondón C, Romero JJ, López S,et al. Local IgE production and positive nasal provocation test in patients with persistent nonallergic rhinitis. J Allergy Clin Immunol 2007; 119: 899-905.

14. Samter M, Becker EL. Ragweed reagins in nasal secretion. Proc Soc Exp Biol Med 1947; 65: 140.

15. Tse KS, Wicher K, Arbesman CE. IgE antibodies in nasal secretions of ragweed-allergic subjects. J Allergy 1970; 46: 352-357.

16. Huggins KG, Brostoff J. Local production of specific IgE antibodies in allergic-rhinitis patients with negative skin tests. Lancet 1975; 26: 148-150.
17. Deuschl H, Johansson SG. Specific IgE antibodies in nasal secretion from patients with allergic rhinitis and with negative or weakly positive RAST on the serum. Clin Allergy 1977; 7: 195-202.

18. Durham SR, Gould HJ, Thienes CP, et al. Expression of epsilon germ-line gene transcripts and mRNA for the epsilon heavy chain of IgE in nasal B cells and the effects of topical corticosteroid. Eur J Immunol 1997; 27: 2899-2906.

19. Coker HA, Durham SR, Gould HJ. Local somatic hypermutation and class switch recombination in the nasal mucosa of allergic rhinitis patients. J Immunol 2003; 171: 5602-5610.

20. Bousquet J, Khaltaev N, Cruz AA, et al; World Health Organization; GA(2)LEN; AllerGenAllergic Rhinitis and its Impact on Asthma (ARIA) 2008 update (in collaboration with the World Health Organization, GA(2)LEN and AllerGen). Allergy 2008; 63(Suppl 86): 8-160.

21. Powe DG, Huskisson RS, Carney AS, Jenkins D, Jones NS. Evidence for an inflammatory pathophysiology in idiopathic rhinitis. Clin Exp Allergy 2001; 31: 864872.

22. Powe DG, Huskisson RS, Carney AS, et al. Mucosal T-cell phenotypes in persistent atopic and nonatopic rhinitis show an association with mast cells. Allergy 2004; 59: 204-212.

23. Blom HM, Godthelp T, Fokkens WJ, et al. Mast cells, eosinophils and IgE-positive cells in the nasal mucosa of patients with vasomotor rhinitis. An immunohistochemical study. Eur Arch Otorhinolaryngol 1995; 252(Suppl 1): S33-S39.

24. van Rijswijk JB, Blom HM, KleinJan A, Mulder PGH, Rijntjes E, Fokkens WJ. Inflammatory cells seem not to be involved in idiopathic rhinitis. Rhinology 2003; 41: 25-30.

25. Ersoy R, Ünsel M, Ardeniz FÖ, et al. The role of nasal provocation test in the differential diagnosis of allergic and non-allergic rhinitis. Asthma Allergy Immunol 2012; 10: 143-148.

26. Carney AS, Powe DG, Huskisson RS, Jones NS. Atypical nasal challenges in patients with idiopathic rhinitis: more evidence for the existence of allergy in the absence of atopy? Clin ExpAllergy 2002; 32: 1436-1440.

27. López S, Rondón C, Torres MJ, et al. Immediate and dual response to nasal challenge with dermatophagoides pteronyssinus in local allergic rhinitis. Clin Exp Allergy 2010; 40: 1007-1014.

28. Rondón C, Campo P, Zambonino MA, et al. Followup study in local allergic rhinitis shows a consistent entity not evolving to systemic allergic rhinitis. J Allergy Clin Immunol 2014; 133: 1026-1031. 
29. Rondon C, Campo P, Eguiluz-Gracia I, et al. Local allergic rhinitis is an independent rhinitis phenotype: the results of a 10-year follow-up study. Allergy 2018; 73: 470-478.

30. Arasi S, Pajno GB, Lau S, Matricardi PM. Local allergic rhinitis: a critical reappraisal from a paediatric perspective. Pediatr Allergy Immunol 2016; 27: 569-573.

31. Hatzler L, Panetta V, Lau S, et al. Molecular spreading and predictive value of preclinical $\mathrm{IgE}$ response to Phleum pratense in children with hay fever. J Allergy Clin Immunol 2012; 130: 894-901.e5.

32. Campo P, Eguiluz-Gracia I, Plaza-Serón MC, et al. Bronchial asthma triggered by house dust mites in patients with local allergic rhinitis. Allergy 2019; 74: 1502-1510.

33. Rondón C, Campo P, Galindo L, et al. Prevalence and clinical relevance of local allergic rhinitis. Allergy 2012; 67: 1282-1288.

34. Yamana Y, Fukuda K, Ko R, Uchio E. Local allergic conjunctivitis: a phenotype of allergic conjunctivitis. Int Ophthalmol 2019; 39: 2539-2544.

35. Fuiano N, Fusilli S, Passalacqua G, Incorvaia C. Allergen-specific immunoglobulin $\mathrm{E}$ in the skin and nasal mucosa of symptomatic and asymptomatic children sensitized to aeroallergens. J Investig Allergol Clin Immunol 2010; 20: 425-430.

36. Fuiano N, Fusilli S, Incorvaia C. A role for measurement of nasal IgE antibodies in diagnosis of alternaria-induced rhinitis in children. Allergol Immunopathol (Madr) 2012; 40: 71-74.

37. Buntarickpornpan P, Veskitkul J, Pacharn P, et al. The proportion of local allergic rhinitis to dermatophagoides pteronyssinus in children. Pediatr Allergy Immunol 2016; 27: 574-579.

38. Duman H, Bostanci I, Ozmen S, Dogru M. The relevance of nasal provocation testing in children with nonallergic rhinitis. Int Arch Allergy Immunol 2016; 170: 115-121.

39. Zicari AM, Occasi F, Di Fraia M, et al. Local allergic rhinitis in children: novel diagnostic features and potential biomarkers. A J Rhinol Allergy 2016; 30: 329-334.

40. Krajewska-Wojtys A, Jarzab J, Gawlik R, Bozek A. Local allergic rhinitis to pollens is underdiagnosed in young patients. AmJ Rhinol Allergy 2016; 30: 198201.

41. Blanca-Lopez N, Campo P, Salas M, Rodriguez CG, et al. Seasonal local allergic rhinitis in areas with high concentrations of grass pollen. J Invest Allergol Clin Immunol 2016; 26: 83-91.
42. Ha EK, Na MS, Lee S, et al. Prevalence and clinical characteristics of local allergic rhinitis in children sensitized to house dust mites. Int Arch Allergy Immunol 2017; 174: 183-189.

43. Tsilochristou O, Kyriakakou M, Manolaraki I, et al. Detection of local allergic rhinitis in children with chronic, difficult-to-treat, non-allergic rhinitis using Multiple Nasal Provocation Tests. Pediatr Allergy Immunol 2019; 30: 296-304.

44. van Hage-Hamsten M, Pauli G. Provocation testing with recombinant allergens. Methods 2004; 32: 281291.

45. Rondón C, Campo P, Herrera R, et al. Nasal allergen provocation test with multiple aeroallergens detects polysensitization in local allergic rhinitis. J Allergy Clin Immunol 2011; 128: 1192-1197.

46. Campo P, Villalba M, Barrionuevo E, et al. Immunologic responses to the major allergen of Olea europaea in local and systemic allergic rhinitis subjects. Clin Exp Allergy 2015; 45: 1703-1712.

47. Bachert C. Nasal provocation test: critical evaluation. In: New Trends in Allergy IV: Springer; 1997:277280.

48. Augé J, Vent J, Agache I, et al. EAACI position paper on the standardization of nasal allergen challenges. Allergy 2018; 73: 1597-1608.

49. Eguiluz-Gracia I, Testera-Montes A, Gonzalez M, et al. Safety and reproducibility of nasal allergen challenge. Allergy 2019; 74: 1125-1134.

50. Meng Y, Wang $Y$, Lou $H$, et al. Specific immunoglobulin $\mathrm{E}$ in nasal secretions for the diagnosis of local allergic rhinitis. Rhinology 2019; 57: 313-320.

51. Rondon C, Eguiluz-Gracia I, Shamji MH, et al. IgE test in secretions of patients with respiratory allergy. Curr Allergy Asthma Rep 2018; 18: 67.

52. Campo P, Del Carmen Plaza-Seron M, EguiluzGracia I, et al. Direct intranasal application of the solid phase of ImmunoCAP® increases nasal specific immunoglobulin E detection in local allergic rhinitis patients. Int Forum Allergy Rhinol 2018; 8: 15-19.

53. Gomez E, Campo P, Rondón C, et al. Role of the basophil activation test in the diagnosis of local allergic rhinitis. J Allergy Clin Immunol 2013; 132: 975-976.e1-e5.

54. Gelardi M, Guglielmi AVN, Iannuzzi L, et al. Local allergic rhinitis: entopy or spontaneous response? World Allergy Organ J 2016; 9: 39.

55. Lee KS, Yu J, Shim D, et al. Local immune responses in children and adults with allergic and nonallergic rhinitis. PLoS One 2016; 11: e0156979. 
56. Keswani A, Peters AT. Complications of rhinitis. Immunol Allergy Clin North Am 2016; 36: 359-366.

57. Jarvis D, Newson R, Lotvall J, et al. Asthma in adults and its association with chronic rhinosinusitis: the GA2LEN survey in Europe. Allergy 2012; 67: 91-98.

58. Burgess JA, Walters EH, Byrnes GB, et al. Childhood allergic rhinitis predicts asthma incidence and persistence to middle age: a longitudinal study. J Allergy Clin Immunol 2007; 120: 863-869.

59. Eguiluz-Gracia I, Pérez-Sánchez N, Bogas G, Campo $\mathrm{P}$, Rondon $\mathrm{C}$. How to diagnose and treat local allergic rhinitis: achallenge for clinicians. J Clin Med 2019; 8: 1062.

60. Rondón C, Blanca-López N, Aranda A, et al. Local allergic rhinitis: allergen tolerance and immunologic changes after preseasonal immunotherapy with grass pollen. J Allergy Clin Immunol 2011; 127: 10691071.
61. Rondón C, Campo P, Blanca-Lopez N, et al. Subcutaneous allergen immunotherapy in patient with "Local Allergic Rhinitis" sensitized to dermatophagoides pteronyssinus. J Allergy Clin Immunol 2015; 135: AB171.

62. Rondón C, Blanca-López N, Campo P, et al. Specific immunotherapy in local allergic rhinitis: a randomized, double-blind placebo-controlled trial with Phleum pratense subcutaneous allergen immunotherapy. Allergy 2018; 73: 905-915.

63. Bozek A, Kolodziejczyk K, Krajewska-Wojtys A, Jarzab J. Pre-seasonal, subcutaneous immunotherapy: a double-blinded, placebocontrolled study in elderly patients with an allergy to grass. Ann Allergy Asthma Immunol 2016; 116: 156-161. 